\title{
Proceedings Paper
}

Tanya Gupta'

\section{Promoting mathematical reasoning and problem solving through inquiry-based relevance focused computer simulations: a stoichiometry lab}

\author{
${ }^{1}$ Department of Chemistry and Biochemistry, South Dakota State University, Brookings 57007, SD, USA, E-mail: \\ tanya.gupta@sdstate.edu
}

\begin{abstract}
:
Simulations model concepts and phenomena. Several researchers have called for an intuitive and user-friendly simulation design to foster conceptual understanding of users. Simulations can also be used to promote mathematical thinking and problem-solving skills of students in various chemistry courses. An example of such use of simulations would be teaching reaction stoichiometry and underlying dimensional analysis for determining the quantity of reactants and products involved in a chemical reaction. In this paper, the author presents an innovative model of a guided-inquiry based simulation for promoting mathematical thinking in chemistry by incorporating mathematical thinking as a component of simulation design. The simulation was implemented in an introductory organic chemistry laboratory course in which a significant gain in pre- and post-test was observed for participating students.
\end{abstract}

Keywords: active-learning, chemistry courses, inquiry-based learning, problem-solving, relevance-focused, simulations, technology integration

DOI: $10.1515 /$ cti-2018-0008

\section{Introduction}

In the past two decades technology-based interventions have found widespread use in various science courses. In chemistry instruction, computer simulations are replacing traditional demonstrations, and laboratory work due to their ease of use, cost effectiveness, and their potential to alleviate safety concerns that accompany a laboratory and classroom demonstrations. A simulation is a dynamic, interactive, scaled down model of the real-world phenomena, and complex natural or synthetic processes that are otherwise difficult to observe or manipulate (Plass, Homer, \& Hayward, 2009; Plass et al., 2012). The purpose of using simulations in chemistry instruction is to help students develop a coherent understanding and explanation of the concepts and theories underlying various reactions and processes and to develop student's critical thinking skills (Akaygun \& Jones, 2013; Falvo \& Suits, 2009; Suits, 2015; Suits \& Sanger, 2013; Suits \& Srisawasdi, 2013).

\section{Simulations for teaching and learning of chemistry and simulation design considerations}

Simulations are effective in helping students visualize particulate level interactions, and in improving problemsolving skills by supplementing sensory experiences of learners (Falvo, 2008; Gerjets \& Hesse, 2004; Stieff \& Wilensky, 2003; Tasker \& Dalton, 2006). Simulations provide new affordances for learning science, particularly for abstract phenomena, and also promote interaction and higher-order thinking about complex scientific ideas (Webb, 2005). This is important in chemistry discipline where a solid grasp of chemistry depends on the understanding of interactions and the particulate nature of matter. These concepts are otherwise hard to visualize without an external aid. Further, simulations are cost effective, safe to use, and convenient to integrate in various instructional settings including lecture and laboratory (Millar \& Osborne, 1998). 
Simulations provide interactivity and also an opportunity to learners to explore the phenomena of interest. Due to their interactive feature, simulations have been found effective in engaging students in classroom and improving student exam scores; their representational competence, and student understanding of specific concepts such as the particulate nature of matter and electrochemistry (Barak, 2013; Barnea \& Dori, 1999; Charistos, Tsipis, \& Sigalas, 2005; Falvo, Urban, \& Suits, 2011). Simulations allow students to explore phenomena and their representations while manipulating variables (Suits \& Diack, 2002). Simulations thus provide a certain degree of control to learners through their interactive features such as play and pause buttons, adjusting variables such as mass, volume etc., using buttons and sliders, and stop, review, and exit functions.

Studies focused on the design features of simulations suggest that simulations should be simple to use; display a balance of information, have audio and visual components in design; allow user control; reduce extraneous cognitive load on learners; and accurately portray the concepts and processes in chemistry (Jones, Jordan, \& Stillings, 2005; Landriscina, 2013; Plass et al., 2009). It is also important to consider the prior knowledge of learners in simulation design because it plays an important role in student use of simulations (Yang, Andre, Greenbowe, \& Tibell, 2003). When simulations foster students' explanation of macroscopic observable chemical reactions at the molecular level they become an effective resource for students' conceptual connections and knowledge construction (Martin \& Mahaffy, 2013; McKenzie et al., 2013).

Studies on the development and application of simulations in chemistry have emphasized an intuitive and user-friendly simulation design to foster conceptual understanding. Simulations can also be used for promoting mathematical thinking particularly in chemistry where students struggle with most fundamental ideas such as stoichiometry. There is a need of variety of such tools that are developed based on well-researched models of teaching and learning and provide a complete picture of a specific or a targeted concept and its relevance in everyday life. This paper highlights the development features of a stoichiometry based simulation called Combustion Lab and its implementation in organic chemistry laboratory with students taking first semester of a two-semester sequence of organic chemistry laboratory course in a mid-western university.

\section{The need for a simulation in stoichiometry}

Learning chemistry involves understanding submicroscopic processes through macroscopic observations and symbolic depiction of various chemical processes. Use of models and analogies makes it easy to grasp various concepts in chemistry that are otherwise too abstract or inexplicable (Bou Jaoude \& Barakat, 2003; Gabel, 1999; Wolfer, 2000). Students often find chemistry to be a difficult and challenging subject. This can be attributed to the chemical processes, which are physically observable (macroscopic) and conceptually abstract. To understand these chemical processes at conceptual level one needs to examine various interactions that take place at the particle level. Students should be able to draw connections between the three representational levels in chemistry - the macroscopic, submicroscopic or particulate level, and the symbolic level for developing a correct conceptual understanding. It is reported that a majority of students treat these three representational levels in a compartmentalized way and view the macroscopic, particulate and symbolic processes to be operating independent of each other (Gulacar, Eilks, \& Bowman, 2014; Marais \& Combrinck, 2009).

Stoichiometry is a fundamental conceptual building block for understanding chemistry. It is necessary to understand quantitative relationships between the various substances that chemically combine to form new substances either naturally or synthetically in a laboratory (Canagaratna, 1993; Figueira, Coch, \& Zepica, 1988; Finley, Stewart, \& Yarroch, 1982). Chemists just do not mix stuff and wait and watch to see what comes out. The experiments in a laboratory are carefully designed such that efficiency can be maximized. Though stoichiometry is fundamental for any chemical reaction, students struggle with the reaction stoichiometry and connecting the three representational levels to coherently understand and apply the law of conservation of mass for a given chemical reaction.

Despite their lack of understanding of stoichiometry, it has been reported that students can solve stoichiometry-based problems correctly. The problem solving attempted by novice students is heavily focused on the surface features of the stoichiometric exercises and problems presented to them (Gabel \& Bunce, 1994; Nurrenbern \& Pickering, 1987; Yarroch, 1985). Several persistent misconceptions have also been reported among students in this area. These misconceptions include incorrect use of subscripts and coefficients in the balanced chemical equation, errors in finding mole-ratios and in using Avogadro's number, limiting reagent and product yield, state of reactants in a reaction, and the reaction conditions (Huddle \& Pillay, 1996; Johnstone, MacDonald, \& Webb, 1977; Kesidou \& Duit, 1993).

Understanding of Stoichiometry is crucial for students pursuing various chemistry courses and aspiring for majors that require basic knowledge of chemistry (Steiner, 1986). It is important to provide several avenues to students in classroom, laboratory settings, and in online instruction through interactive visual tools to 
strengthen student understanding of important concepts. Specifically, new simulation models that are student centered need to be developed and explored. Through this paper the usefulness of an innovative simulation called Combustion Lab is explored. The paper introduces a new-student centered model of Simulation Design that incorporates Learning Cycle Approach and knowledge evaluation embedded throughout the simulation.

\section{A coherent mental model connecting three levels of representation and the learning cycle approach}

Expert problem-solvers often use various models and representations to arrive at the correct solution (Chi, Feltovich, \& Glaser, 1981; Gupta, 2017; Kozma \& Russell, 1997). The conceptual understanding of chemistry relies on acquisition and integration of various principles through representations at the macroscopic level, particulate level (microscopic) and the symbolic level. A coherent mental model of student will encompass all three levels (Gupta, Ziolkowski, Albing, \& Mehta, 2017; Johnstone, 1993). In addition, such a model would either incorporate or be presented along with other student-centered approaches that emphasize scientific exploration, problem-solving and critical thinking skills. One such research-based approach is the Learning Cycle.

\section{Learning cycle approach to inquiry teaching}

The goal of inquiry-based instruction is to advance the scientific understanding of students and to also develop the scientific thinking and reasoning skills like those of experts in the discipline (Gupta, Burke, Mehta, \& Greenbowe, 2015). Learning cycle (LC) is a student-centered inquiry-based approach based on the constructivist paradigm of teaching and learning. The LC has three stages of (a) concept exploration, (b) concept invention or concept introduction and, (c) concept application, and concept evaluation that are conducted in a sequence (Abraham, 1998; Lawson, Abraham, \& Renner, 1989).

In the exploration stage learners engage in hands-on classroom, laboratory, or online activities. The focus of this phase is data collection, observations, and seeking patterns. In the concept introduction stage students are introduced to the concept. This usually occurs by instructor facilitation and during discussion with peers based on the patterns observed. In this stage student engage in meaning making and develop explanations for the trends they notice in data. Instructor helps students by asking appropriate questions to connect student prior knowledge to student experiences of the activity and introduces students to the new concept(s) and terminologies.

In the concept application stage of learning cycle students take their understanding further by applying it to a new problem. Students may also review, revise, and reinforce their understanding by working on a similar problem in a different context. This could involve reading a research paper, solving problems, or designing the next stage of the activity or experiment. At this stage the focus is on the knowledge of students and how it can be applied further and reexamined. The final stage of concept evaluation is assessment based. In this stage the student knowledge is evaluated. This could involve different activities such as further reading, group discussions, reflection, exams and quizzes.

The Combustion Lab Simulation incorporates all three representational levels (macroscopic, particulate and symbolic) and the Learning Cycle Model. It advances the concept evaluation of the Learning Cycle Approach further by evaluating student knowledge at several points. This is also an advancement of the Learning Cycle Model that reflects in the design of the Combustion Lab simulation as described in this paper. The simulation design involves assessment of student prior knowledge and student understanding at each stage of the LC approach (knowledge evaluation component). The details of Combustion Lab Simulation and its design are presented in the next section of this paper.

\section{Stoichiometry through Combustion Lab simulation}

Author and her research team have developed the Combustion Lab simulation considering the prior research on simulations and their design aspects as briefly discussed in prior section. Combustion Lab simulation is a 2$\mathrm{D}$ activity that incorporates the Learning Cycle approach. There are four buttons on the opening screen. These buttons (Figure 1) are designed according to the key stages of the Learning Cycle as (a) Prior Knowledge Activation - PKA, (b) Exploration Activity - EA (c) Concept Introduction - CI, and (d) Post-Activity Application - 
PAA. The knowledge evaluation stage of the Learning Cycle is embedded within each component of Combustion Lab simulation and also included in the Combustion Lab simulation as the Post-Activity Application in the simulation. The Combustion Lab simulation is segmented to cover different examples of the stoichiometry of combustion reactions.

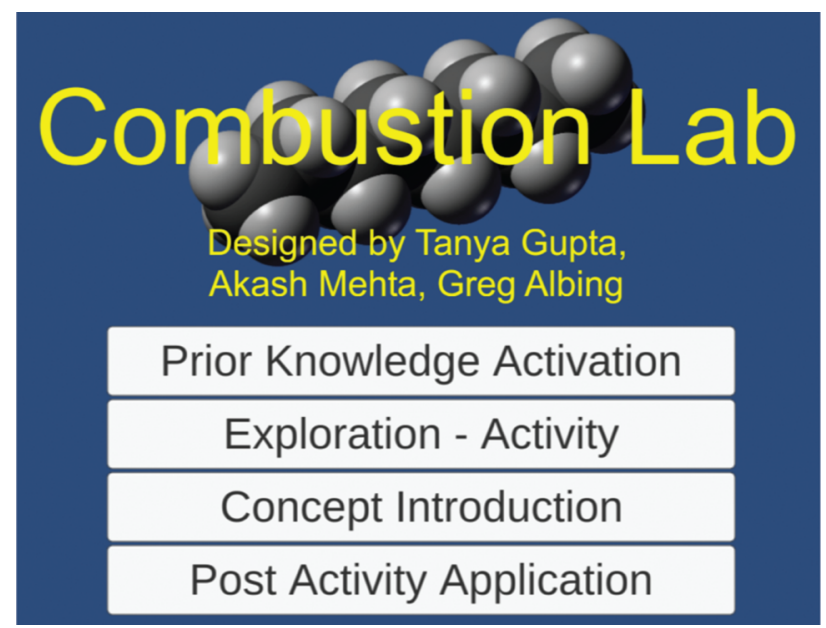

Figure 1: Combustion Lab simulation.

As displayed in Figure 1, a user can begin the activity by clicking on any of the four buttons in the front screen panel. Author recommends that the users start from PKA and follow each sequence in order for an authentic Learning Cycle-based inquiry experience.

The goal of Combustion Lab simulation is to engage students in the process of inductive discovery of the stoichiometry of combustion reactions and a simultaneous evaluation of student knowledge through various problems embedded within the simulation. The simulation can run on different platforms (Windows, Mac, and Linux computers). Hardware requirements for these simulations are very low. Very few simulation objects are in use at any one time due to its segmented and focused design. Efforts are underway to develop versions for mobile devices.

\section{a) Prior Knowledge Activation}

The PKA segment of simulation is focused on assessing student prior knowledge through a multiple-choice type question bank (Figure 2). The question bank in this component also includes questions adapted from chemical concept inventory (CCI) by Mulford and Robinson (2002). A written consent was obtained for these questions to include them in PKA component. These questions are based on various topics such as dimensional analysis, physical and chemical changes, understanding of coefficients and subscripts in a reaction. Questions in PKA segment also include identifying and classifying the reactions based on balanced equations, naming a reactant or a product, or the correct formula of a compound. The PKA component comes first prior to exploration phase. In the PKA segment, users are quizzed on 10 randomized questions. As a user answers these questions, he/she can see their score on the top right corner of the screen based on the correctness of their response. The maximum score for the PKA is 10 points for 10 questions.

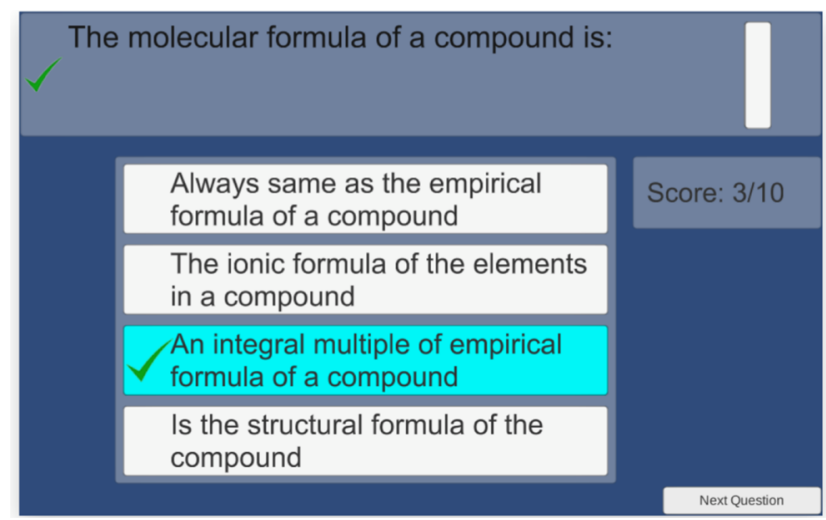

Figure 2: Sample question from PKA segment of combustion lab. 


\section{b) Concept Exploration through Exploration Activity (EA)}

The Concept Exploration (CE) component of simulation is called Exploration Activity (EA) (Figure 3). On clicking the EA button one can see four individual combustions reactions for different fuels that are further segmented into a series of macroscopic, particulate, and symbolic representations. These include methane, propane, butane and octane. With the use of arrows one can explore a given reaction and navigate through four different fuels. The initial representation of the combustion reaction for any selected fuel is at the macroscopic level. After clicking the next arrow, one can see the symbolic representation of the equation and balance the equation for a combustion reaction. The objective is to allow the user to connect the macroscopic process with the symbolic representation. After clicking next button, the user experiences the molecular representation as space filling models of the same reaction. The representation is accompanied with the sliders for the user to see the relation between different amounts of reactants and products involved in the reaction in the units of moles, grams, kilograms, liters and gallons. This function of Combustion Lab is aimed at helping a learner connect the changes in number that correspond to the different units that are used. The learner can see the change in numbers as they use the slider. When the user picks a molecule (reactant or product) in the reaction and slides, the value for the amount of reactant and products accordingly (increases or decreases). Figure 4 and Figure 5 represent the symbolic representations and molecular representations of these reactions during the concept exploration.

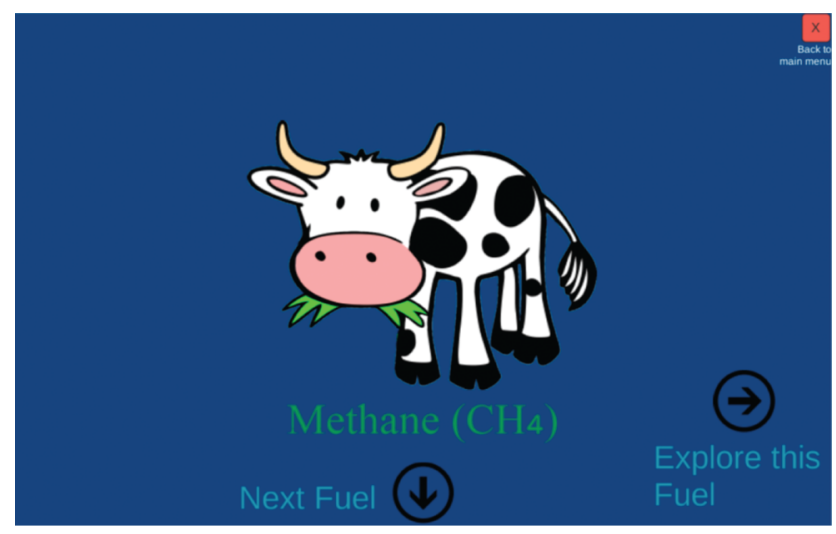

Figure 3: Concept exploration phase as depicted by the macroscopic process.

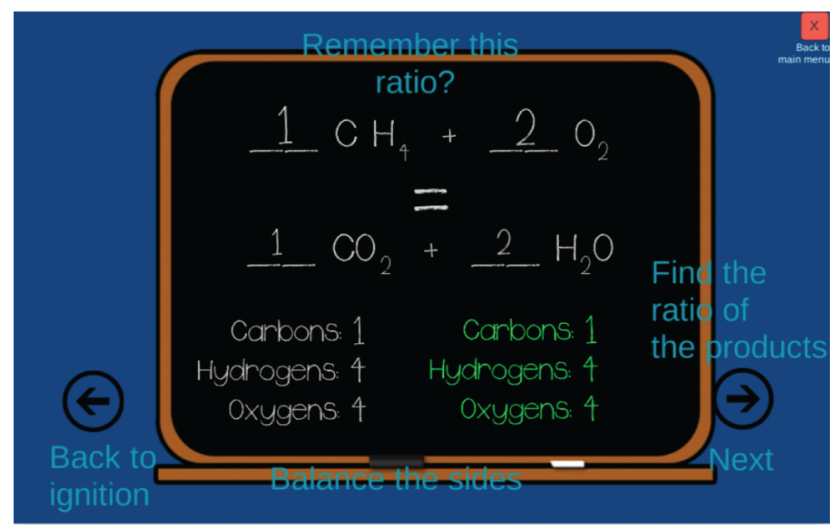

Figure 4: Symbolic representation - determining the coefficients to balance equation. 


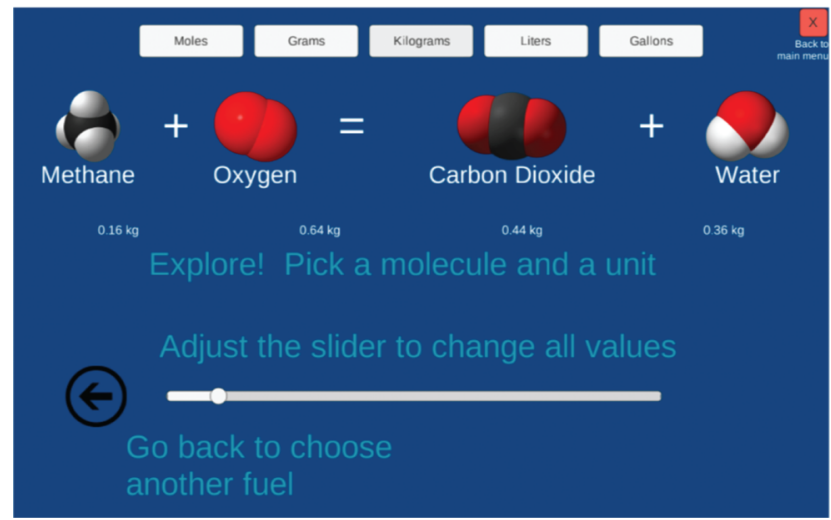

Figure 5: Screenshot of a space-filling molecular representation and showing relation between different units (quantities) for reactants and products.

As mentioned, there are four combustion reactions in the Combustion Lab. For this paper, only one component of the exploration-activity is presented as an example. When a student explores an activity that involves combustion of octane - the student is presented with sliders to adjust the ratio of air to fuel. In case of octane, once the student arrives at the correct ratio (25:2) there is a flame observed in the simulation at the moving piston that indicates the ignition (Figure 6).

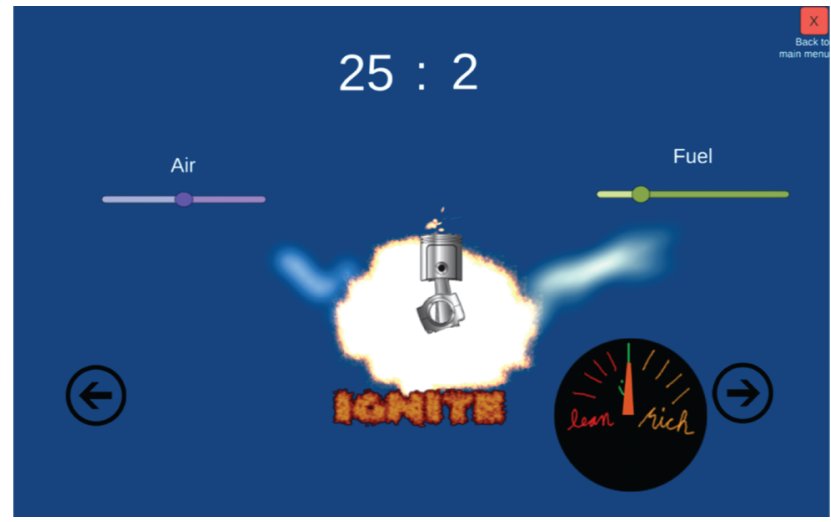

Figure 6: Combustion reaction depicting the stoichiometry of octane with sliders for adjusting air-fuel ratio.

Incorrect ratios will indicate dark fumes and some sparks. As the fuel ignites, a forward arrow appears on the bottom right corner of the screen. This allows the user to proceed to the next sub-segment, which is the blackboard (see Figure 4 for digital chalkboard with symbolic representation or reaction equation). On the digital blackboard the user needs to balance the reaction equation for the reaction by entering coefficients for reactants and products. If the user enters the correct coefficients for the reaction, the number of atoms on both sides of the reaction equations match-up and turn green. Incorrect coefficients are displayed by a red color for the number of atoms and the user is asked to retry the coefficients.

A forward arrow at the bottom right of simulation window leads users to the next screen of the Combustion Lab wherein the conversion factors for various amounts of reactants and products are provided along with the space-filled models of each reactant and product (see Figure 5 for molecular level representation with various units). In this component of exploration students can use sliders and set the amount of reactants and products in various units such as moles, grams, kilograms, liters and gallons. As students change the amount on the slider, the amount of reactants and products displayed underneath molecular representation also changes. This enables students to view the quantity of reactants and products in various units (conversion factors). Students can click on the unit buttons to see various amounts of reactants and products for each of the five units presented in this simulation. These can be done for each of the four combustion reaction activities. The EA involves inbuilt trials and errors for students, which is consistent with the LC approach. Students can play with various ratios for each reaction and try different coefficients and explore conversions for different amounts of reactants and products. 


\section{c) Concept Introduction}

The next button is Concept Introduction (CI). In the CI section students are presented very brief information on coefficients, law of conservation of mass, combustion reactions and the impact of the use of fossil fuels on global warming. Figure 7 depicts the CI component of simulation. As mentioned, this is a brief informative section that introduces students to the Law of Conservation (LOC), combustion reactions, fossil fuels, the applications of the LOC and its symbolic representation through a balanced chemical equation.

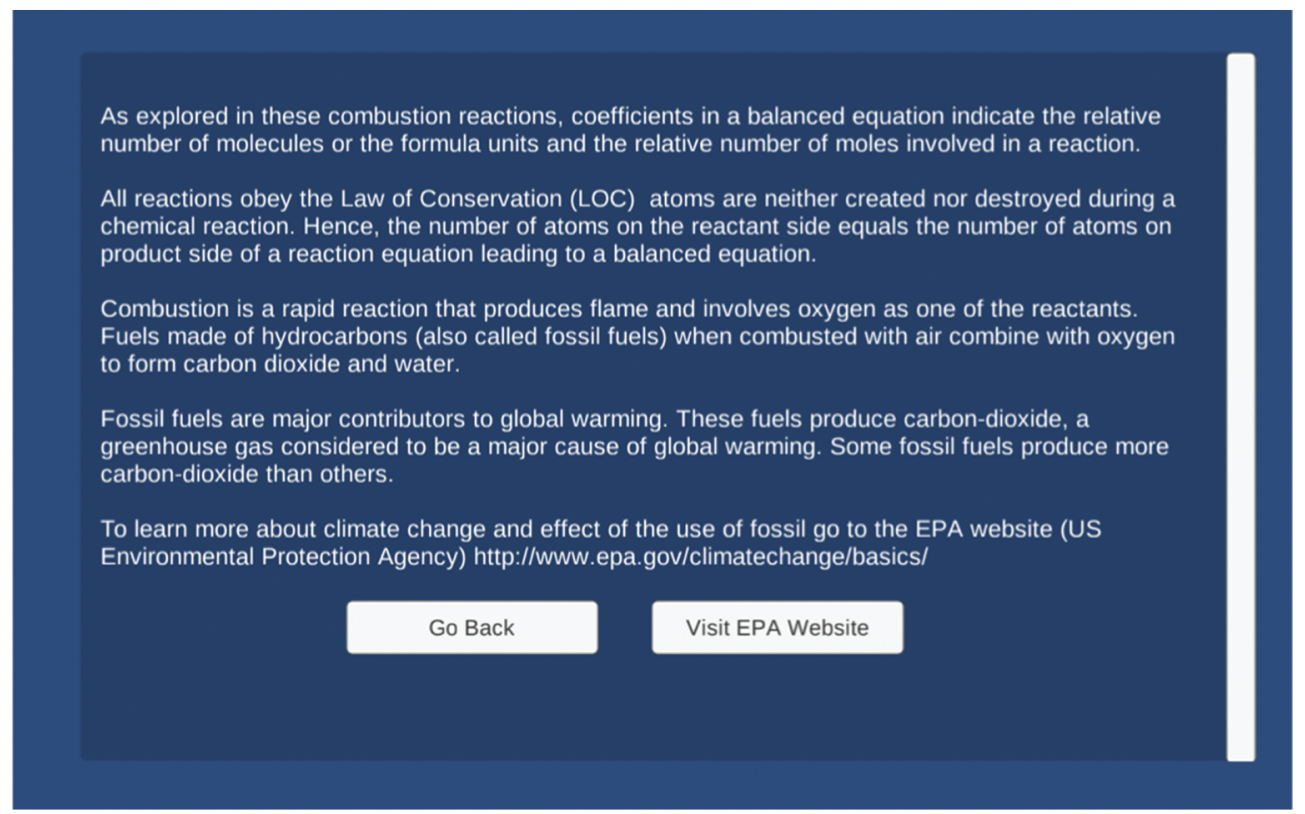

Figure 7: Concept introduction component of combustion lab.

There are two buttons in this component of Combustion Lab (Figure 8). The Go Back button allows user to revisit any of the four combustion activities. Visit EPA website (Environmental Protection Agency) button allows the user to access the EPA website from within the Combustion Lab. This inbuilt feature provides users an opportunity to understand the relevance of the stoichiometry of combustion reactions in light of the effects of these fuels on global warming leading to climate change. Students can explore the EPA website by a direct click of a button from within the simulations and do some more research on the use of fossil fuels and its connection to global warming.

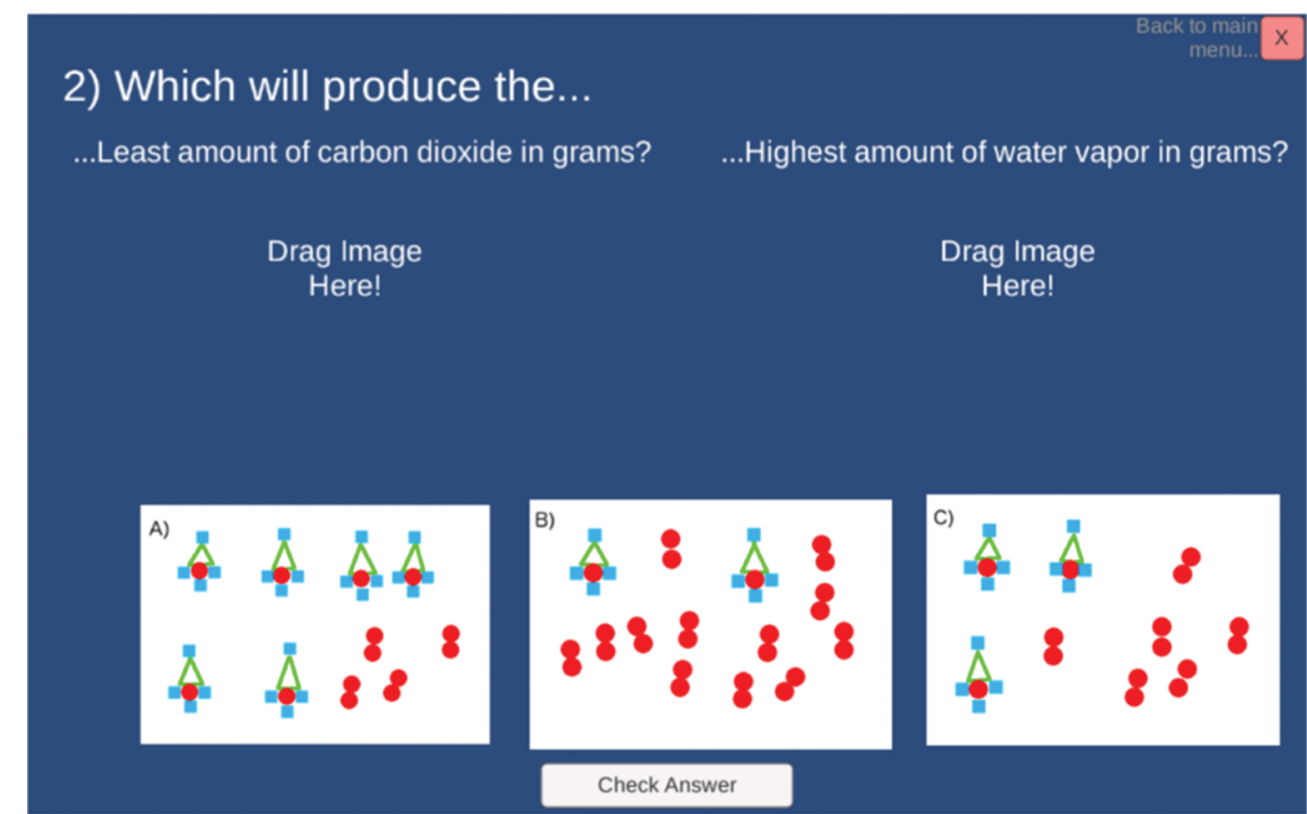

Figure 8: Concept application and knowledge evaluation through post activity application problems. 


\section{d) Post Activity Application (PAA)}

The last component of the Combustion Lab is Concept Application and Evaluation Phase of the Learning Cycle Model and is titled Post Activity Application (PAA). PAA involves stoichiometry-based problems, problems on limiting reagent involving particulate or submicroscopic representations, and real-world problems for example: calculating the gas mileage and cost for a round-trip to Disneyland, and the resultant quantity of a greenhouse gas (carbon-dioxide) emitted by car (Figure 8: PAA problem).

PAA problems cover basic to advanced understanding of the stoichiometry of combustion reactions, and also aim at providing students an opportunity to reflect on the impact of using fossil fuels on a daily basis in terms of the greenhouse gas released into the environment by a simple act of round-trip for leisure. Students receive an immediate feedback for the responses entered in this section. If the student response is incorrect, they are asked to try again. A red flash based in the check answer button indicates an incorrect response. The next section describes implementation of the Combustion-Lab to study its effectiveness.

\section{Implementation and the study of the effectiveness of Combustion Lab Simulation}

After developing the simulation on Combustion Lab incorporating the Learning Cycle and Prior Knowledge Activation, the next important step was to study the impact of this new simulation model on student learning. To achieve this objective, the combustion Lab was implemented at an undergraduate level organic chemistry course to answer the research question on the impact of Combustion Lab Simulation on student performance on stoichiometry-based problems. The theoretical framework of constructivism, symbolic interactionism and model-based learning and teaching informed this study.

From a constructivist perspective, the construction of scientific knowledge among learners needs to be coherent, viable, and consistent with the established principles of the discipline (Duckworth, 1964; Herron, 1975; Kretchmar \& Zeichner, 2016). Learners should have sufficient opportunities through carefully designed activities to develop correct understanding of scientific processes. Symbolic interactionism is a based on the need for symbols and their importance in knowledge construction (Blumer, 1969). This is especially relevant for chemistry (stoichiometry) as the development of the knowledge in this discipline to a large extent relies on the use of symbols as a language (formulas and equations), and microscopic and macroscopic representation of phenomena.

Models are also important for scientific reasoning and comprehension. Scientists often construct and use models to explore and explain phenomena, to arrive at correct explanations, and to build evidence and scientific argumentation (Campbell, Oh, Maughn, Kiriazis, \& Zuwallack, 2015; Clement, 2000). Model-based teaching and learning can improve student's ability to make sense of scientific phenomena by enabling students to construct causal explanations. A target qualitative model, which is the simplified analogous model of specific phenomena or a concept such as stoichiometry can be very helpful for students to develop scientifically coherent conceptual models. Various models of chemical processes when presented to students in the form of representations, animations and simulations can positively impact student understanding of chemistry (Tasker \& Dalton, 2006).

\section{Research methods}

A sequential explanatory mixed-methods approach was used for this study. A sequential explanatory study is characterized by collection of both quantitative and qualitative data. Quantitative data is collected and analyzed first followed by qualitative data to support or explain quantitative findings (Creswell \& Plano Clark, 2011). The qualitative data in the form of student written laboratory reports was integral in explaining and interpreting the results of the quantitative data of the tests. For this paper, the author will specifically focus on the quantitative data and supportive qualitative student data from the laboratory reports that highlights the effectiveness of the combustion lab simulation.

\section{Data collection and analysis}

Study involved participation of students from the first semester of a two-semester sequence of an organic chemistry laboratory course. The simulation was implemented as an alternate online laboratory activity. All students 
enrolled in this course had been introduced to Stoichiometry during the two-semester sequence of general chemistry, which is a perquisite for the organic chemistry course. It was anticipated that students have sufficient prior knowledge to engage in a stoichiometry based online lab with a minimal direction on downloading and doing the laboratory activity. The activity was assigned to students during the second week before students engaged in any wet laboratory on organic synthesis that require stoichiometry-based calculations from the students (mole ratios and limiting reagents).

The learning management system folders were timed and organized in a way that students would first do the randomized pre-quiz, then download and run the Combustion Lab during the laboratory section meeting for the same amount of time $(2 \mathrm{~h}$ and $50 \mathrm{~min})$ as their regular in laboratory session meeting. Students were required to write and submit a laboratory report in the D2L dropbox at the conclusion of the activity. After students submitted their laboratory report, the randomized post-quiz opened on D2L for 30 min. Students were electronically graded for pre- and post-quiz. The laboratory reports were graded by the course instructor and followed the same rubric for all participating students. Toward the end of semester, students were given the laboratory practical exam, which contained multiple-choice questions that were based on questions from PKA, EA, CI and PAA questions from the Combustion Lab. The exam was conducted in the laboratory during the final exam's week.

About 215 students (82.4\%) consented to participate in this study. The students taking this chemistry laboratory course are mainly pre-med, pre-pharmacy, pre-dental or allied health science majors. About $43 \%$ participants were males and $57 \%$ were females. Students enrolled in the laboratory were also enrolled in the co-requisite organic lecture course. It is important to note that the implementation of combustion lab simulation was done in the laboratory and the data is collected only from the laboratory component of the course. The data for student performance on the pre- and post-quiz was downloaded from the D2L as Microsoft Excel files. The files were then cleaned and organized - students who did not consent to participation in the research study were omitted from data analysis. Students with incomplete data (missing a quiz or laboratory report) were also eliminated which led to a sample size of 193 students.

The back-end user data generated from the simulation use by students was downloaded as Microsoft Excel spreadsheets. These files were then organized into the different sections of the simulation - Prior Knowledge Activation (PKA), post-activity application (PAA), and Concept-Introduction (CI) for generating response frequencies and studying simulation user behavior. A two-tailed matched pairs t-test was performed (Howell, 2007) to compare student performance on pre- and post-quiz and for PKA and PAA combustion lab questions. For analyzing qualitative data, the student reports were coded for anonymity and uploaded in the Atlas.ti software for qualitative coding. Interrater reliability for qualitative reports was established by having two independent raters code the data and discuss the outcomes of coding. The inter-rater agreement was found to be $89 \%$ for first set of codes and $91 \%$ for second level of coding.

\section{Results and discussion student performance on stoichiometry problems}

A summary of mean pre- and post-test scores and paired samples t-test is provided in Table 1. The results of two-tailed t-test indicate a statistically significant difference $(p=0.008 ; \alpha=0.05, D F, 192)$ between student scores. The assessment was based on reaction stoichiometry and the randomized questions were similar in levels of difficulty level from pre-to post-test but not exactly same (wording or numbers in questions differed due to random assignment). The same weighting coefficient was applied to all randomized questions for consistency. Student performance also significantly improved on stoichiometry-based questions in laboratory final exams.

Table 1: Comparison of student performance.

\begin{tabular}{lrrl}
\hline $\mathbf{N}=\mathbf{1 9 3})$ & $\begin{array}{r}\text { Mean score } \\
\text { (total } \\
\text { points=10) }\end{array}$ & $\begin{array}{r}\text { Standard } \\
\text { deviation }\end{array}$ & Paired t-test \\
\hline Pre-test & 6.90 & 2.14 & $\begin{array}{l}\left.\mathrm{p}=0.0008^{*} \text { (Significant at } \alpha=0.05\right) \text { DF } \\
=192 ; 95 \% \text { confidence }\end{array}$ \\
Post-test & 7.60 & 2.25 & \\
$\begin{array}{l}\text { Prior knowledge activation score } \\
\text { Lab practical exam score on }\end{array}$ & 5.84 & 0.39 & $\begin{array}{l}\left.\mathrm{p}=0.00001^{*} \text { (Significant at } \alpha=0.05\right) \\
\text { sfoichiometry }\end{array}$ \\
\hline
\end{tabular}

*Significant at $\alpha=0.05 ;$ DF $192 ; 95 \%$ confidence. 
The quantitative results show an improvement in student understanding of stoichiometry from pre- to posttest on use of Combustion Lab simulation. The simulation seems to have helped students understand the underlying stoichiometry of combustion reactions. Student scores on prior knowledge activation component of the simulation was taken as a baseline (pre-test) to compare to student performance on the laboratory practical exam. The difference between the two mean scores was significant ( $p=0.00001$ at $\alpha=0.05$ ). Based on quantitative results, it is evident that students were able to translate their knowledge to solving post-test and laboratory exam problems correctly. These problems required understanding and application of the stoichiometry to arrive at the correct answer.

Analysis of qualitative data generated from student written laboratory reports showed that (a) students for most part had a better understanding of stoichiometry and they applied law of conservation of mass appropriately and (b) students found stoichiometry to be very relevant to their everyday life. Table 2 presents representative qualitative student quotes highlighting student understanding and specific examples used by students that showed the relevance of stoichiometry.

Table 2: Qualitative student responses, and examples of relevance.

\begin{tabular}{|c|c|c|}
\hline Code & $\begin{array}{l}\text { Representative student quote from laboratory } \\
\text { report }\end{array}$ & $\begin{array}{l}\text { Example of relevance from laboratory } \\
\text { report }\end{array}$ \\
\hline $\begin{array}{l}\text { Recognize the law of } \\
\text { conservation to be } \\
\text { the underlying } \\
\text { concept and apply it } \\
\text { correctly. }\end{array}$ & $\begin{array}{l}\text { Coefficients in combustion reactions help to } \\
\text { indicate the number of moles in a reaction. The Law } \\
\text { of Conservation of mass is the reason we have to } \\
\text { balance equations because matter cannot be } \\
\text { destroyed or created. In combustion oxygen must } \\
\text { be on the reactant side. }\end{array}$ & $\begin{array}{l}\text { Also, fossil fuels produce a greenhouse } \\
\text { gas which causes global warming. }\end{array}$ \\
\hline $\begin{array}{l}\text { Concepts can be } \\
\text { explored through } \\
\text { reactions in } \\
\text { simulation. }\end{array}$ & $\begin{array}{l}\text { All reactions obey the Law of Conservation (LOC) } \\
\text { atoms are neither created nor destroyed during a } \\
\text { chemical reaction. Combustion is a rapid reaction } \\
\text { that produces flame and involves oxygen as one of } \\
\text { the reactants. I explored different reaction and how } \\
\text { they ignite with fuel and air. }\end{array}$ & $\begin{array}{l}\text { An example of stoichiometry in } \\
\text { everyday life is cooking. We follow } \\
\text { recipe to prepare food and not just mix } \\
\text { things in any order. }\end{array}$ \\
\hline $\begin{array}{l}\text { Balanced equations } \\
\text { are symbolic } \\
\text { representations of } \\
\text { reactions. }\end{array}$ & $\begin{array}{l}\text { Combustion reactions occur when a fuel and air } \\
\text { combine to form carbon dioxide and water. The } \\
\text { Law of Conservation states that atoms are neither } \\
\text { created nor destroyed during a chemical reaction. } \\
\text { So that means all the reactants on the left-hand side } \\
\text { have to match the products on the right-hand side. } \\
\text { They need to be even, hence a balanced equation. }\end{array}$ & $\begin{array}{l}\text { I use stoichiometry while driving and } \\
\text { also in medications. We have to know } \\
\text { the amount of active ingredient we take } \\
\text { that undergoes a reaction in our body } \\
\text { to cure for example stomach acidity. }\end{array}$ \\
\hline
\end{tabular}

\section{Conclusions and further research}

The study shows that simulations such as Combustion Lab can aid in student understanding. The study involved assessment of student performance on pre- and post-test and final exams in the laboratory course and a qualitative analysis of student written laboratory reports based on the simulation. The simulation was implemented as an online laboratory activity, which limits the scope of implementation. It will be worthwhile to implement this activity in a classroom setting or in a face-to-face laboratory structure. Students were allocated the same time frame for this activity as the regular laboratory session. Despite the limitation the study has important implications for the use of simulations to facilitate scientific inquiry and promote relevance of chemistry. Simulations can also be used to foster student knowledge and understanding when used in multiple ways. An important use of simulations such as Combustion Lab for instructor would be to examine the user-data to identify and address gaps in student understanding in the real-time and promote collaborative technology-based learning in the classroom.

This paper was part of an online discussion hosted by the ACS CHED CCCE (Committee on Computers in Chemical Education). These are free online conferences and you do not need be a member of ACS or CHED to participate. More information can be obtained at the website, https://confchem.ccce.divched.org/. 


\section{Acknowledgments}

Author acknowledges the contributions and inputs of Dr. Akash Mehta and Mr. Gregory Albing toward developing Combustion Lab Simulation.

\section{References}

Abraham, M. R. (1998). The learning cycle approach as a strategy for instruction in science. In K. Tobin \& B. Fraser (Eds.), International handbook of science education (pp. 513-524). Kluwer: The Netherlands.

Akaygun, S., \& Jones, L. L. (2013). Animation or simulation: Investigating the importance of interactivity for learning solubility equilibria. In ]. P. Suits \& M. J. Sanger (Eds.), Pedagogic role of animations and simulations in chemistry courses. ACS Symposium Series, vol. 1142 (pp. 127-159). Washington, DC: American Chemical Society.

Barak, M. (2013). Making the unseen seen: Integrating 3D molecular visualizations in elementary, high school, and higher education. In J. P. Suits \& M. J. Sanger (Eds.), Pedagogic roles of animations and simulations in chemistry courses. ACS Symposium Series, vol. 1142 (pp. 273-291). Washington, DC: American Chemical Society.

Barnea, N., \& Dori, Y. J. (1999). High school chemistry students' performance and gender differences in a computerized molecular modeling learning environment. Journal of Science Education and Technology, 8(4), 257-271.

Blumer, H. (1969). Symbolic interactionism: Perspective and method. Englewood Cliffs, N]: Prentice-Hall.

Bou Jaoude, S., \& Barakat, H. (2003). Students' problem solving strategies on stoichiometry and their relationships to conceptual understandings and learning approaches. Electronic Journal of Science Education, 7(3), 1-42.

Campbell, T., Oh, P. S., Maughn, M., Kiriazis, N., \& Zuwallack, R. (2015). A Review of Modeling Pedagogies: Pedagogical Functions, Discursive Acts, and Technology in Modeling Instruction. EURASIA Journal of Mathematics, Science \& Technology Education, 11(1), 159-176.

Canagaratna, S. G. (1993). Is dimensional analysis the best we have to offer? Journal of Chemical Education, 70 (1), 40.

Charistos, N. D., Tsipis, C. A., \& Sigalas, M. P. (2005). 3D molecular symmetry Shockwave: A web application for interactive visualization and three dimensional perception of molecular symmetry. Journal of Chemical Education, 82(11), 1741.

Chi, M. T., Feltovich, P. J., \& Glaser, R. (1981). Categorization and representation of physics problems by experts and novices. Cognitive Science, $5(2), 121-152$.

Clement, J. (2000). Analysis of Clinical Interviews: Foundations and Model Viability. In Kelly, A. E., \& Lesh R. (Eds.), Handbook of Research Design in Mathematics and Science Education. (pp. 547-589). Mahwah, N]: Lawrence Erlbaum Associates.

Creswell, J. W., \& Plano Clark, V. L. (2011). Designing and conducting mixed methods research. California: Sage.

Duckworth, E. (1964). Piaget rediscovered. Journal of Research in Science Teaching, 2(3), 172-175.

Falvo, D. A. (2008). Animations and simulations for teaching and learning molecular chemistry. International Journal of Technology in Teaching and Learning, 4(1), 68-77.

Falvo, D. A., \& Suits, J. P. (2009). Cender and spatial ability and the use of specific labels and diagrammatic arrows in a micro-level chemistry animation. Journal of Education and Computational Research, 41(1), 83-102.

Falvo, D. A., Urban, M. J., \& Suits, J. P. (2011). Exploring the impact of and perceptions about interactive, self-explaining environments in molecular-level animations. Center for Educational Policy Studies Journal, 1(4), 45-61.

Figueira, A. R., Coch, J., \& Zepica, M. (1988). Teaching stoichiometry. Journal ofChemical Education, 65(12), 1060-1061.

Finley, F. N., Stewart, J., \& Yarroch, W. L. (1982). Teacher's perceptions of important and difficult science content. Science Education, 66(4), 551538.

Gabel, D. S., \& Bunce, D. M. (1994). Research on Problem Solving: Chemistry. In D. L. Gabel (Ed.), Handbook of Research on Science Teaching and Learning. A Project of the National Science Teachers Association. New York: Macmillan Publishing Company.

Gabel, D. (1999). Improving teaching and learning through chemistry education research: A look to the future. Journal ofChemical Education, 76(4), 548-554.

Cerjets, P. H., \& Hesse, F. W. (2004). When are powerful learning environments effective: The role of learner activities and of students' conceptions of educational technology. International Journal of Educational Research, 41(6), 445-465. DOI: 10.1016/j.ijer.2005.08.011.

Gulacar, O., Eilks, I., \& Bowman, C. R. (2014). Differences in general cognitive abilities and domain-specific skills of higher- and lowerachieving students in stoichiometry. Journal ofChemistry Education, 91(7), 961-968.

Cupta, T. (2017). A study of student problem-solving strategies using ATLAS.ti. In Gupta, T. (Ed.), Computer-aided data analysis in chemical education research (CADACER): Advances and avenues. ACS Symposium Series, vol. 1260 (pp. 133-155). Washington, DC: American Chemical Society.

Cupta, T., Burke, K. A., Mehta, A., \& Greenbowe, T. J. (2015). Impact of guided-inquiry-based instruction with a writing and reflection emphasis on chemistry students' critical thinking abilities. Journal of Chemical Education, 92(1), 32-38.

Gupta, T., Ziolkowski, Z. P., Albing, G., \& Mehta, A. (2017). Simulations in chemistry for conceptual understanding and assessment of student knowledge, Ch. 8. In peer-reviewed Levin, I. \& Tsybulsky D. (Eds.), Optimizing STEM education with advanced ICTs and simulations (pp. 186218). Hershey, PA: ICI Clobal. DOI: 10.4018/978-1-5225-2528-8.

Herron, J. D. (1975). Piaget for chemists. Journal of Chemical Education, 52(3), 146-150.

Howell, D. C. (2007). Statistical methods for psychology. California: Sage.

Huddle, P. A., \& Pillay, A. E. (1996). An in-depth study of misconceptions in stoichiometry and chemical equilibrium at a South African university. Journal of Research in Science Teaching, 33(1), 65-77.

Johnstone, A. H. (1993). The development of chemistry teaching: A changing response to changing demand. Journal ofChemical Education, 70(9), 701-705. 
Johnstone, A. H., MacDonald, J. J., \& Webb, G. (1977). Misconceptions in school thermodynamics. Physics Education, 12, $248-251$.

Jones, L. L., Jordan, K. D., \& Stillings, N. A. (2005). Molecular visualization in chemistry education: the role of multidisciplinary collaboration. Chem. Educ. Res. Pract, 6(3), 136-149.

Kesidou, S., \& Duit, R. (1993). Students' conceptions of the second law of thermodynamics - An interpretative study. Journal of Research in Science Teaching, 30(1), 85-106.

Kozma, R. B., \& Russell, J. (1997). Multimedia and understanding: Expert and novice responses to different representations of chemical phenomena. Journal of Research in Science Teaching, 34(9), 949-968.

Kretchmar, K., \& Zeichner, K. (2016). Teacher Prep 3.0: A Vision for Teacher Education to Impact Social Transformation. Journal of Education for Teaching, 42(4), 417-433.

Landriscina, F. (2013). Simulation-based learning. Simulation \& Learning: A model-centered approach (pp. 99-36). Springer: New York.

Lawson, A. E., Abraham, M. R., \& Renner, J. W. (1989). A theory of instruction: Using the learning cycle to teach science concepts and thinking skills (Monograph, Number One). Kansas State University Manhattan, KS: National Association for Research in Science Teaching.

Marais, F., \& Combrinck, S. (2009). An approach to dealing with the difficulties undergraduate chemistry students experience with stoichiometry. South African Journal of Chemistry, 62, 88-96.

Martin, B., \& Mahaffy, P. (2013). Using visualizations of the science behind climate change to change the climate of science teaching. In J. P. Suits, \& M. J. Sanger (Eds.), Pedagogic roles of animations and simulations in chemistry courses. ACS Symposium Series, vol. 1142 (pp. 411-440). Washington, DC: American Chemical Society.

McKenzie, L., Versprille, A., Towns, M., Mahafy, P., Martin, B., \& Kirchoff, M. (2013). Visualizing the chemistry of climate change (VC3Chem): online resoruces for teaching and learning chemistry through the rich conttext if climate science. Paper Presented at the American Ceophysical Union, Fall meeting, 2013, abstract \#ED31E-04, http://adsabs.harvard.edu/abs/2013ACUFMED31E..04M. (accessed, August, 2017).

Millar, R., \& Osborne, J. F. (1998). Beyond 2000: Science education for the future. London: King's College London.

Mulford, D. R., \& Robinson, W. R. (2002). An Inventory for Alternate Conceptions among First-Semester Ceneral Chemistry Students. Journal ofChemical Education, 79(6), 739-744.

Nurrenbern, S. C., \& Pickering, M. (1987). Concept learning versus problem solving: Is there a difference? Journal ofChemical Education, 64(6), 508-510.

Plass, J. L., Homer, B. D., \& Hayward, E. O. (2009). Design factors for educationally effective animations and simulations. Journal of Computing in Higher Education, 21(1), 31-61.

Plass, J. L., Milne, C., Homer, B. D., Schwartz, R. N., Hayward, E. O., \& Jordan, T., ... Barrientos ]. (2012). Investigating the effectiveness of computer simulations for chemistry learning. Journal of Research in Science Teaching, 49(3), 394-419.

Steiner, R. P. (1986). Teaching stoichiometry. Journal of Chemical Education, 63(12), 1048.

Stieff, M., \& Wilensky, U. (2003). Connected chemistry-incorporating interactive simulations in chemistry classroom. Journal of Science Education and Technology, 12(3), 285-302.

Suits, J. P. (2015). Design of dynamic visualizations to enhance conceptual understanding in chemistry courses. In ]. C. Martinez \& E. SerranoTorregrosa (Eds.), Chemistryeducation: Best practices, opportunities, and trends. Cermany: Wiley-VCH.

Suits, J. P., \& Diack, M. (2002). Instructional design of scientific simulations and modeling software to support student construction of perceptual to conceptual bridges. World Conference on Educational Multimedia Hypermedia and Telecommunication, 1, 1904-1909.

Suits, J. P., \& Sanger, M. J. (2013). Dynamic visualization in chemistry courses. In J. P. Suits \& M. J. Sanger (Eds.), Pedagogic roles of animations and simulations in chemistry courses. ACS Symposium Series, vol. 1142 (pp. 1-13). Washington, DC: American Chemical Society.

Suits, J. P., \& Srisawasdi, N. (2013). Use of an interactive computer-simulated experiment to enhance students' mental models of hydrogen bonding phenomena. In J. P. Suits \& M. J. Sanger (Eds.), Pedagogic roles of animations and simulations in chemistry courses, ACS Symposium Series, vol. 1142 (pp. 241-271). Washington, DC: American Chemical Society.

Tasker, R., \& Dalton, R. (2006). Research into practice: Visualization of the molecular world using animations. Chemistry Education Research and Practice, 7(2), 141-159.

Webb, M. E. (2005). Affordances of ICT in science learning: Implications for an integrated pedagogy. International Journal of Science Education, $27(6), 705-735$.

Wolfer, A. J. (2000). Introductory college chemistry students' understanding of stoichiometry: Connections between conceptual and computational understandings and instruction. (Unpublished doctoral dissertation). Oregon State University, Corvallis, OR.

Yang, E., Andre, T., Greenbowe, T. J., \& Tibell, L. (2003). Spatial ability and the impact of visualization/animation on learning electrochemistry. International Journal of Science Education, 25(3), 329-349.

Yarroch, W. L. (1985). Student understanding of chemical equation balancing. Journal of Research in Science Teaching, 22(5), 449-459. 